Article

\title{
Scenario Analysis of Livestock Carrying Capacity Risk in Farmland from the Perspective of Planting and Breeding Balance in Northeast China
}

\author{
Zhe Zhao ${ }^{1}$, Xiangzheng Deng ${ }^{2,3, *}$, Fan Zhang ${ }^{2,3}$, Zhihui Li ${ }^{2,3}{ }^{\mathbb{D}}$, Wenjiao Shi ${ }^{2,3}$, Zhigang Sun ${ }^{2,3}$ \\ and Xuezhen Zhang ${ }^{2,3}$ (D) \\ 1 School of Economics, Liaoning University, Shenyang 110136, China; zhaozhe@lnu.edu.cn \\ 2 University of Chinese Academy of Sciences, Beijing 100101, China; zhangf.ccap@igsnrr.ac.cn (F.Z.); \\ lizhihui@igsnrr.ac.cn (Z.L.); shiwj@lreis.ac.cn (W.S.); sun.zhigang@igsnrr.ac.cn (Z.S.); \\ xzzhang@igsnrr.ac.cn (X.Z.) \\ 3 Institute of Geographic Sciences and Natural Resources Research, Chinese Academy of Sciences, \\ Beijing 100101, China \\ * Correspondence: dengxz@igsnrr.ac.cn; Tel.: +86-139-1132-5867
}

\section{check for}

updates

Citation: Zhao, Z.; Deng, X.;

Zhang, F.; Li, Z.; Shi, W.; Sun, Z.;

Zhang, X. Scenario Analysis of

Livestock Carrying Capacity Risk in

Farmland from the Perspective of

Planting and Breeding Balance in

Northeast China. Land 2022, 11, 362.

https://doi.org/10.3390/

land 11030362

Academic Editor: Manuel Pulido Fernádez

Received: 9 February 2022

Accepted: 1 March 2022

Published: 2 March 2022

Publisher's Note: MDPI stays neutral with regard to jurisdictional claims in published maps and institutional affiliations.

Copyright: (C) 2022 by the authors. Licensee MDPI, Basel, Switzerland. This article is an open access article distributed under the terms and conditions of the Creative Commons Attribution (CC BY) license (https:// creativecommons.org/licenses/by/ $4.0 /)$.

\begin{abstract}
In this paper, we selected the northeast region as a study area from the perspective of soil nutrient demand, calculated the livestock carrying capacity of farmland under three scenarios where nitrogen nutrient accounts for 35\% (low level), 45\% (medium level), and 55\% (high level) of fertilization, and carried out a risk analysis. The results show that the scale of husbandry breeding is expanding and the scale of the planting industry has remained basically unchanged. Under the three scenarios, there were 23 regions where the livestock manure exceeded the maximum value that could be absorbed by farmland in 2008 and 28 regions in 2019. These regions in the potential area are mostly located in Heilongjiang province and the regions in the restricted area are mostly located in Liaoning Province. On the whole, the northeast region is generally faced with the problem of livestock overloading, and the insufficient utilization and treatment capacity of livestock manure poses a huge threat to regional ecological security. Based on this, adjusting the structure of regional planting and breeding, promoting the development of the livestock manure processing industry, enhancing the production capacity of organic fertilizer, and constructing an integrated pattern of regional planting and breeding are effective ways to realize the sustainable utilization of farmland in northeast China.
\end{abstract}

Keywords: livestock carrying capacity risk; planting and breeding balance; northeast China

\section{Introduction}

Farmland is not only a crucial agricultural resource and production factor, but also the key to ensuring food production. The northeast region is an important grain production base in China [1]. This region is endowed with rich black soil resources, and is also one of the four largest black land regions in the world, where it is very suitable for farming [2]. The existing farmland in the northeast region is $3.59 \times 107 \mathrm{ha}$, the grain output accounts for nearly one-quarter of the national total grain output, and the exported commercial grain accounts for one-third of the national total commercial grain [3]. The northeast region has made an outstanding contributions to ensuring national food security and is known as China's first granary. However, in recent years, with the rapid development of the livestock-breeding industry, a large amount of livestock and poultry manure and other forms of waste have not been effectively treated, which has led to serious ecological and environmental problems [4]. The northeast region is gradually evolving from an "ecological functional area" to an "ecologically fragile area", and problems such as the degradation of physicochemical properties and ecological functions have become increasingly prominent, posing a serious threat to the stability of the national food security foundation and 
regional ecological security [5-7]. At present, the phenomenon of planting and breeding separation in northeast China has become very common. The excessive application of chemical fertilizers and pesticides on farmland has seriously threatened the security of water and soil resources in these areas. If coupled with the large-scale discharge of livestock manure and other wastes, pollutants from the planting and breeding industries entering the environment will greatly exceed the carrying capacity of the farmland, which will create serious pollution problems $[8,9]$.

Against the background of many uncertainties, such as COVID-19, international trade, and extreme weather, the Central Economic Work Conference has clearly identified the "farmland issue" as one of the eight key tasks to be tackled in 2021. Additionally, the No. 1 Central Document clearly stated in 2021 that it is necessary to "adopt the measures of 'long teeth' and implement the strictest farmland protection system". President Xi Jinping has repeatedly made a series of important instructions regarding the protection of farmland, such as "protecting farmland like protecting giant pandas, firmly keeping the red line of farmland protection, and protecting farmland that is a major issue for more than one billion people to eat ..." ". The question of how to combine the ecological and economic benefits of farmland resources and explore a coordinated development path to ensure food security and ecological security has become an important issue related to the sustainable development of northeast China. At present, the imbalance of the agro-pastoral ecological structure caused by the separation of planting and breeding, which has broken the relationship between material circulation and energy flow within agriculture under the traditional farming system, is the core cause of the continuous deterioration of local ecological environments [10-12]. Additionally, the demand for livestock products has surged significantly due to the changes in the dietary structure of residents, which has led to the continuous expansion of the husbandry production scale [13], and resulting problems such as overgrazing will also lead to ecological problems such as soil erosion and land desertification. Especially with the intensification of the global climate change process, soil erosion and other problems are becoming more serious [14,15]. In the context of the separation of planting and breeding, the fertilizers needed for the planting industry have been gradually replaced by chemical fertilizers. On the one hand, this leads to environmental pollution and resource waste due to the failure of the return of livestock manure to fields and resource underutilization. On the other hand, the excessive use of chemical fertilizers in pursuit of yield improvement also leads to serious environmental problems [16]. In the long run, this will inevitably threaten regional ecological security and national food security.

A large number of studies have shown that livestock manure has useful properties, containing nitrogen, phosphorus, potassium, and other nutrients necessary for crop production, and is an important nutrient source for improving soil fertility [17]. However, overuse of manure can also lead to environmental pollution and soil compaction $[18,19]$. In recent years, governments at all levels have successively issued a series of measures to promote the resource utilization of livestock breeding waste, emphasizing the important role of livestock manure in the high-quality development of agriculture. Thus, relocating the production activities of husbandry to the agricultural ecosystem, reconstructing the combination mode and ecological link between agriculture and husbandry, and ensuring that the breeding waste is digested in the ecological cycle system of agriculture and husbandry will undoubtedly effectively increase soil organic matter content $[20,21]$. The combination of planting and breeding and the cycle of farming and grazing are considered to be the most effective solutions at present [22]. Therefore, based on the idea of planting and breeding balance, scientifically measuring the nutrient demand of regional crop growth and the nutrient availability of livestock manure has become the key to adjusting regional planting and raising structure, reducing the application of chemical fertilizer, reducing environmental pollution, and achieving high-quality agricultural development [23]. In this context, research on the regional livestock carrying capacity of farmland is becoming increasingly abundant [24]. The regional livestock carrying capacity of farmland refers to 
the maximum stock of livestock and poultry that can be supported by farmland in a given region under the condition of the sustainable operation of the land ecosystem, and it can also be popularly understood as the ability of a farmland to absorb livestock and poultry excrement [25].

The existing research generally studies the livestock carrying capacity of farmland from the perspective of meeting the nutrient requirements of crops, through constructing the farmland consumption model of livestock breed waste based on the soil nitrogen and phosphorus nutrient-balance method [23,26-29]. If the regional crops can absorb the livestock breeding waste in an equal proportion, the balance between planting and breeding in the region can be considered to be achieved [29]. In 2018, the Ministry of Agriculture and Rural Affairs of the People's Republic of China issued the "Technical Guidelines for the Measurement of Farmland Carrying Capacity of Livestock Manure" (hereinafter referred to as the Guide), which requires that the livestock carrying capacity should be calculated based on the balance between the nitrogen supply of manure and the nitrogen demand of plants. Subsequently, the Nitrogen Nutrient Balance Method (NNBM) has been widely used in the field of analyzing the carrying capacity of livestock breeding [30,31]. However, farmland consumption of livestock manure is mainly via absorption by crops of nitrogen, phosphorus, and other elements emitted by livestock. Clearly, the ability to absorb livestock manure of farmland varies under different fertilization intensities, and the corresponding livestock carrying capacity of farmland will also be significantly different, and the existing research has not considered the effect of different fertilization intensities [32]. Therefore, calculating the carrying capacity of livestock breeding under different fertilization intensities is helpful for providing references for determining the reasonable livestock breeding scale and adjusting the industrial layout within the region.

However, based on this, we selected the northeast region as a study area, which includes Liaoning Province, Jilin Province, and Heilongiiang Province, from the perspective of soil nutrient demand. We calculated the livestock carrying capacity of farmland under the three scenarios where nitrogen nutrient accounts for 35\% (low level), $45 \%$ (medium level), and $55 \%$ (high level) of fertilization, and we carried out a risk analysis. This is expected to provide decision support for optimizing the layout of livestock breeding, adjusting the production structure of planting, reducing local pollution, and building a modern agricultural and animal husbandry policy system with balanced planting and breeding.

\section{Material and Methodology}

\subsection{Study Area}

The northeast region is located in the northeastern part of China, including three provinces of Liaoning, Heilongiiang, and Jilin, with a total area of $787,300 \mathrm{~km}^{2}$ (Figure 1). Among them, Heilongjiang Province includes 13 cities with a total area of $473,000 \mathrm{~km}^{2}$, Jilin Province includes 9 cities with a total area of $187,400 \mathrm{~km}^{2}$, and Liaoning Province includes 14 cities with a total area of $145,700 \mathrm{~km}^{2}$ [33]. On the whole, the northeast region has a temperate monsoon climate, and the terrain is mainly dominated by mountains and plains. It is the main grain production base in China and has made important contributions to ensuring national food security, and it also known as the "stabilizer" and "ballast stone" of China's grain production [34]. However, due to the imbalance of the planting and breeding structure, the ecological environmental problems are becoming more and more prominent. On the one hand, this leads to the lack of nourishment of organic fertilizers and the decline in soil organic matter; on the other hand, it also leads to the destruction of the ecological environment [19]. Therefore, determining the scale of planting and breeding that matches the carrying capacity of arable land is the key to realizing the mutual connection, coordinated promotion, and common development of planting and breeding, so that agricultural resources can be fully and effectively utilized. 


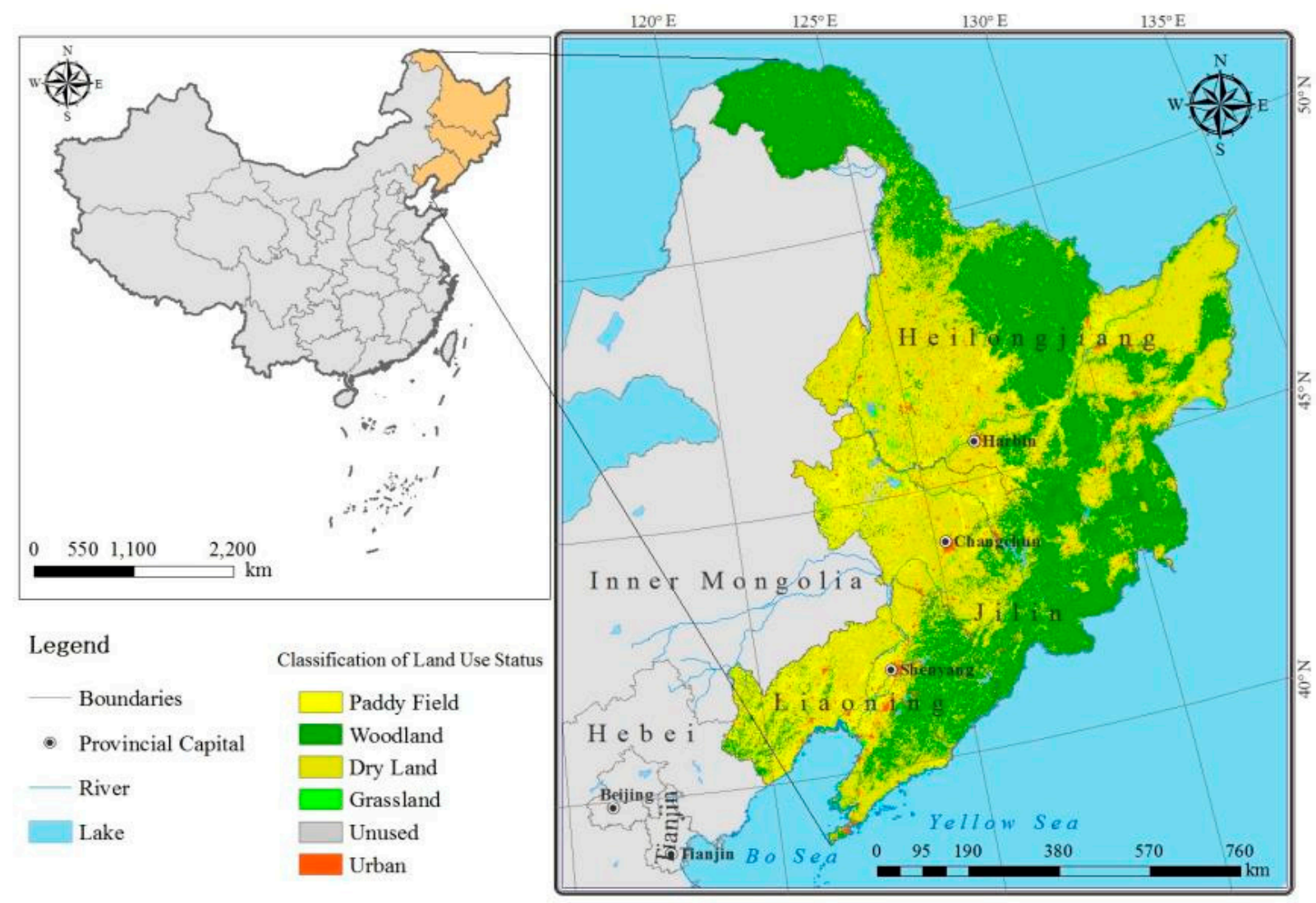

Figure 1. Study area.

\subsection{Experimental Design}

\subsubsection{Data Source}

The research data in this paper (amount of livestock and poultry breeding, sown area, annual crop yield, etc.) come from China Animal Husbandry Yearbook (2009-2020), Agricultural Statistical Yearbook (2009-2020), Heilongjiang Statistical Yearbook (2009-2020), Jilin Statistical Yearbook (2009-2020), Liaoning Statistical Yearbook (2009-2020), and related agricultural survey data; China's provincial administrative division data come from the National Science and Technology Basic Conditions Platform-Earth System Science Data Sharing Platform. Additionally, the correlation coefficients involved in this paper all come from the "Technical Guide for the Measurement of Land Carrying Capacity of Livestock and Poultry Manure" issued by the General Office of the Ministry of Agriculture in March 2018.

\subsubsection{Methodology}

According to the main planting and breeding species in the Northeast region, we analyzed the nitrogen nutrient supply of four types of livestock manure (pig, cattle, sheep, poultry) and the nitrogen nutrient demand data of regional plants (rice, wheat, corn, sorghum, millet, potatoes, soybean, cotton, vegetable, melons), and calculated the livestock carrying capacity of farmland from 2008 to 2019 by using the Nitrogen Nutrient Balance Method (NNBM). Considering that the absorption of livestock manure in farmland mainly depends on the absorption of nitrogen, phosphorus, and other elements in livestock emissions by crops, the absorptive capacity of farmland will be varied under different fertilization intensities. Based on this, on the basis of referring to relevant research $[35,36]$, we considered three different fertilization intensities, that is, the proportion of nitrogen nutrient in fertilization being 35\%,45\%, and 55\%, respectively. Finally, we determined the livestock carrying capacity of farmland under different scenarios. 


\subsubsection{Indicator Accounting}

(1) Regional livestock manure nitrogen nutrient supply accounting

According to the Guide, the regional livestock manure nitrogen nutrient supply accounting was based on the nitrogen nutrient supply of livestock manure and the nitrogen nutrient demand for crop growth. The nitrogen nutrient demand for crop growth was determined according to soil fertility, crop type and yield, and the proportion of manure use. The nitrogen nutrient supply of livestock and poultry manure was determined according to the level of livestock breeding and manure nutrient production. Moreover, for ease of calculation and analysis, other major livestock and poultry were converted into the number of pigs (pig equivalent) according to the relationship in the Guide, as follows:

$$
Q=Q p i g+\frac{20}{3} Q c o w+\frac{10}{3} Q c a t t l e+\frac{2}{5} Q \text { sheep }+\frac{1}{25} \text { Qpoultry }
$$

where $Q$ represents the standard pig production, and $Q_{\text {pig }}, Q_{\text {cow }}, Q_{\text {cattle, }}, Q_{\text {sheep }}, Q_{\text {poultry }}$ represent the number of pigs, cows, cattle, sheep and poultry to slaughter, respectively.

Therefore, the level of regional livestock manure nitrogen nutrient supply is as follows:

$$
N_{s}=Q \times 0.007 \times 10,000
$$

where $N_{s}$ represents the level of regional livestock manure nitrogen nutrient supply, and 0.007 represents nitrogen supply per unit pig equivalent $(t)$.

(2) Accounting for the regional manure nitrogen nutrient requirement for crops

The manure nitrogen requirement of crops is the total amount of nitrogen required for the complete growth cycle of field plants, as follows:

manure nitrogen nutrient requirement of crops $=\frac{\text { regional manure nitrogen nutrient requirement of crops }}{\text { seasonal utilization of manure }} \times$ the proportion of nitrogen nutrient supplied by fertilization $\times$ the proportion of manure in fertilization seasonal utilization of manure

regional manure nitrogen nutrient requirement of crops $=$ total crops production $\times$ nutrient requirements per unit of yield

where scenarios of the proportion of nitrogen nutrient in fertilization were determined to be $35 \%, 45 \%$, and $55 \%$, respectively, and according to the Guide, the proportion of manure in fertilization was determined to be $50 \%$. The seasonal utilization of manure was determined to be $30 \%$. Additionally, the nutrient requirements per unit yield of different crops are shown in Table 1.

Table 1. Recommended nitrogen demand for field crop yields per $100 \mathrm{~kg}$.

\begin{tabular}{llllll}
\hline Type of Crops & Rice & Wheat & Corn & Sorghum & Millet \\
\hline $\mathrm{N}(\mathrm{kg} / \mathrm{t})$ & 20.9 & 30 & 25.2 & 24.8 & 38 \\
\hline Type of crops & potatoes & soybean & cotton & vegetable & melons \\
\hline $\mathrm{N}(\mathrm{kg} / \mathrm{t})$ & 5.1 & 75 & 117 & 3.2 & 4 \\
\hline
\end{tabular}

(3) Regional livestock carrying capacity of farmland accounting

The regional livestock carrying capacity of farmland is the maximum livestock stock in a certain area under the condition of sustainable operation of the farmland ecosystem, as follows:

regional livestock carrying capacity of farmland $=\frac{\text { regional manure nitrogen requirement of crops }}{\text { nitrogen supply of manure per unit pig equivalent }}$ 
(4) The risk coefficient of regional livestock carrying capacity of farmland

This paper referred to Fu et al. (2020) and selected the risk coefficient of regional livestock carrying capacity of farmland by $r$, which was used to quantitatively describe the risk of overloading of regional livestock breeding. If $\mathrm{r} \leq 1$ (potential area), it means that the livestock breeding in this region has not exceeded the upper limit of farmland carrying capacity, and the breeding scale can be appropriately expanded; if $1<\mathrm{r}<2$ (general risk area), it means that the livestock manure has exceeded the upper limit of farmland absorption, which will have a negative affect on the regional ecological environment; if $r$ $>2$ (restricted area), it means that the livestock manure has far exceeded the upper limit of farmland absorption, and if left unchecked, there will be irreversible effects on the environment. The higher $\mathrm{r}$ is, the greater risk of environmental pollution is. This paper defines three risk levels: low, medium, and high, corresponding to the potential zone, general risk zone, and restricted zone (Table 2) [32], as follows:

$$
r=\frac{\text { the existing number of livestock breeding in the region }}{\text { regional livestock carrying capacity of farmland }}
$$

Table 2. The risk coefficient classification for regional livestock carrying capacity of farmland.

\begin{tabular}{cccc}
\hline Risk Coefficient & $\mathbf{r} \leq \mathbf{1}$ & $\mathbf{1}<\mathbf{r}<\mathbf{2}$ & $\mathbf{r} \geq \mathbf{2}$ \\
\hline risk level & low & medium & high \\
\hline risk partition & potential area & general risk area & restricted area \\
\hline
\end{tabular}

\section{Results}

\subsection{Changes in Livestock Manure Nitrogen Nutrient Supply in the Northeast Region}

Figure 2 shows the results of livestock manure nitrogen nutrient supply in the Northeast region. On the whole, the livestock manure nitrogen nutrient supply in each region shows a trend of steady growth, indicating that the scale of husbandry breeding is expanding, which is basically consistent with the research results of domestic and foreign scholars on the characteristics of livestock breeding stages [37-39].
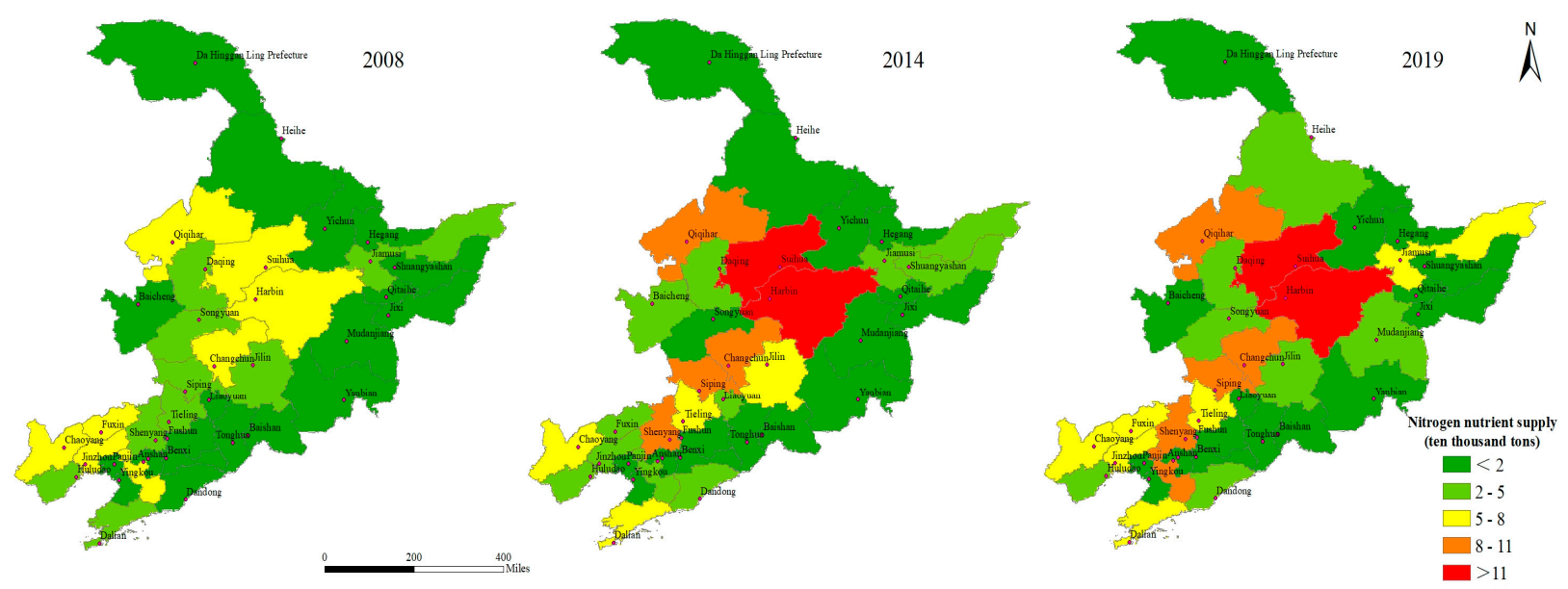

Figure 2. The livestock manure nitrogen nutrient supply in the northeast region in 2008, 2014, 2019.

From the perspective by year, in 2008, the maximum value of livestock manure nitrogen nutrient supply appeared in Changchun, which was 79,210 tons. Additionally, Suihua (71,530), Jinzhou (71,520), Qiqihar $(61,170)$, and Harbin $(51,350)$ were all at high levels. In 2019, the maximum value appeared in Suihua, which was 12.192 tons, and except for Changchun (9.585), Qiqihar (8.636), and Harbin (11.946), Shenyang (10.217) and Anshan (8.895) were also at a relatively high level. From the perspective of change trends, except for 
Hegang, Benxi, Jinzhou, and Liaoyang, which showed a downward trend, the rest of the regions all showed an upward trend, but the magnitude of the increase was quite different. Among them, Harbin, Jiamusi, Shuangyashan, and Shenyang have higher growth rates, with annual growth rates of $11.05 \%, 9.27 \%, 7.25 \%$, and $10.42 \%$, respectively.

\subsection{Changes in Manure Nitrogen Nutrient Requirement of Crops in the Northeast Region}

Figure 3 shows the manure nitrogen nutrient requirement of crops under three scenarios where the proportions of nitrogen nutrient in fertilization are $35 \%, 45 \%$, and 55\%, respectively. On the whole, the change range of the manure nitrogen nutrient requirement of crops in the northeast region was not very obvious. Except for Harbin and Suihua, which showed a relatively obvious growth trends, the change range of the rest of the regions was quite small, or increased or decreased slightly, indicating that the scale of the planting industry has remained basically unchanged.
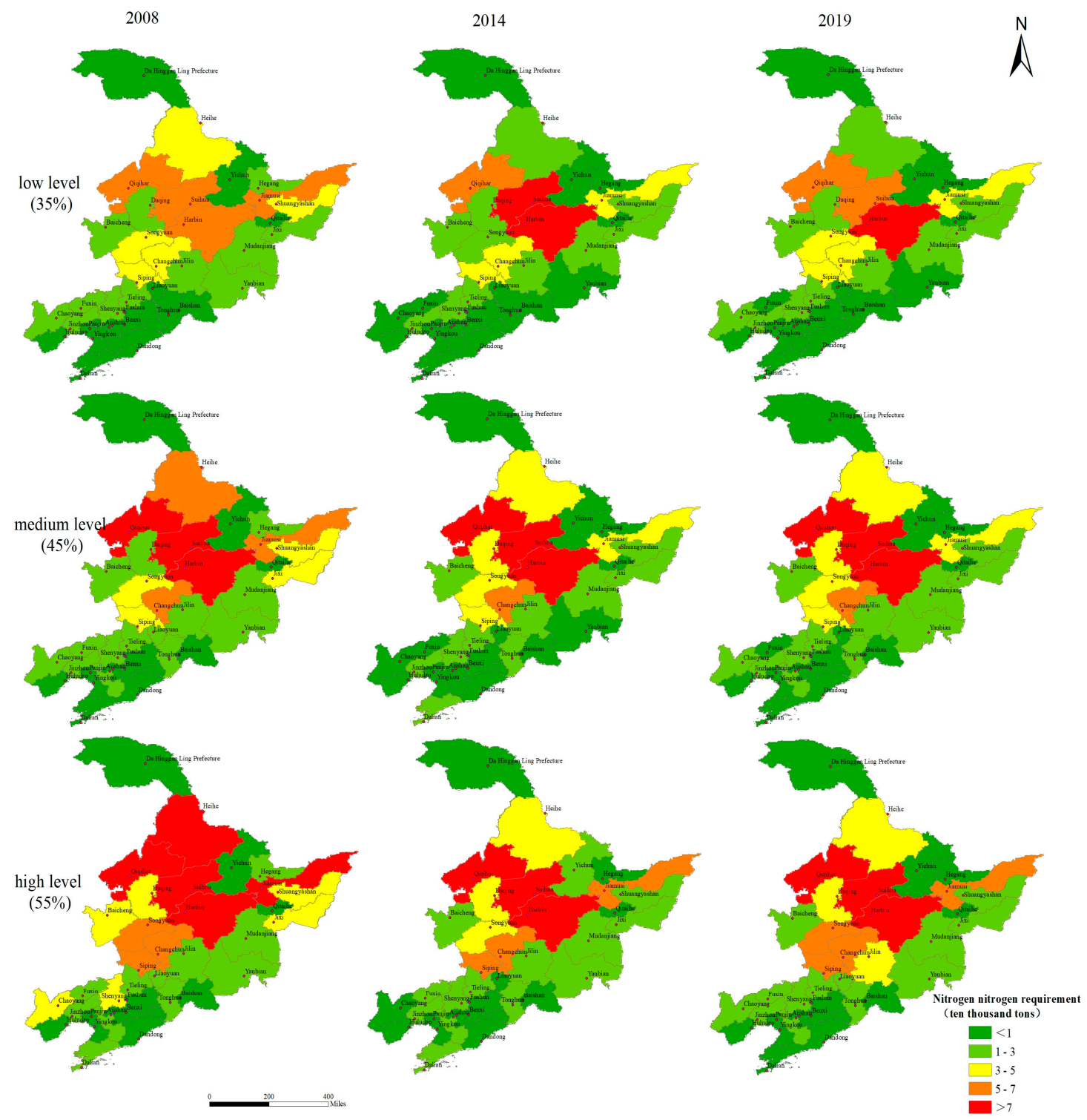

Figure 3. The manure nitrogen nutrient requirement of crops in the northeast region in 2008, 2014, and 2019.

\subsection{Changes in Livestock Carrying Capacity of Farmland in the Northeast Region}

Figure 4 shows the livestock carrying capacity of farmland under three scenarios where the proportion of nitrogen nutrient in fertilization is $35 \%, 45 \%$, and $55 \%$, respectively. 
On the whole, the livestock carrying capacity in each region shows a downward trend, indicating that the capacity of farmland to absorb livestock manure was declining. However, it can be clearly seen from Figure 4 that the livestock carrying capacity of farmland in the $55 \%$ (high level) scenario is higher than in the $45 \%$ (medium level) scenario, and the $45 \%$ scenario is also significantly higher than the 35\% (low level) scenario, indicating that the higher the proportion of nitrogen nutrient in fertilization, the higher the livestock carrying capacity of farmland. Additionally, combined with the pig equivalent level of livestock breeding in each region, it can be seen that the livestock production in 27 regions exceeded the actual carrying capacity in 2008, and in 29 regions it was exceeded in 2019.
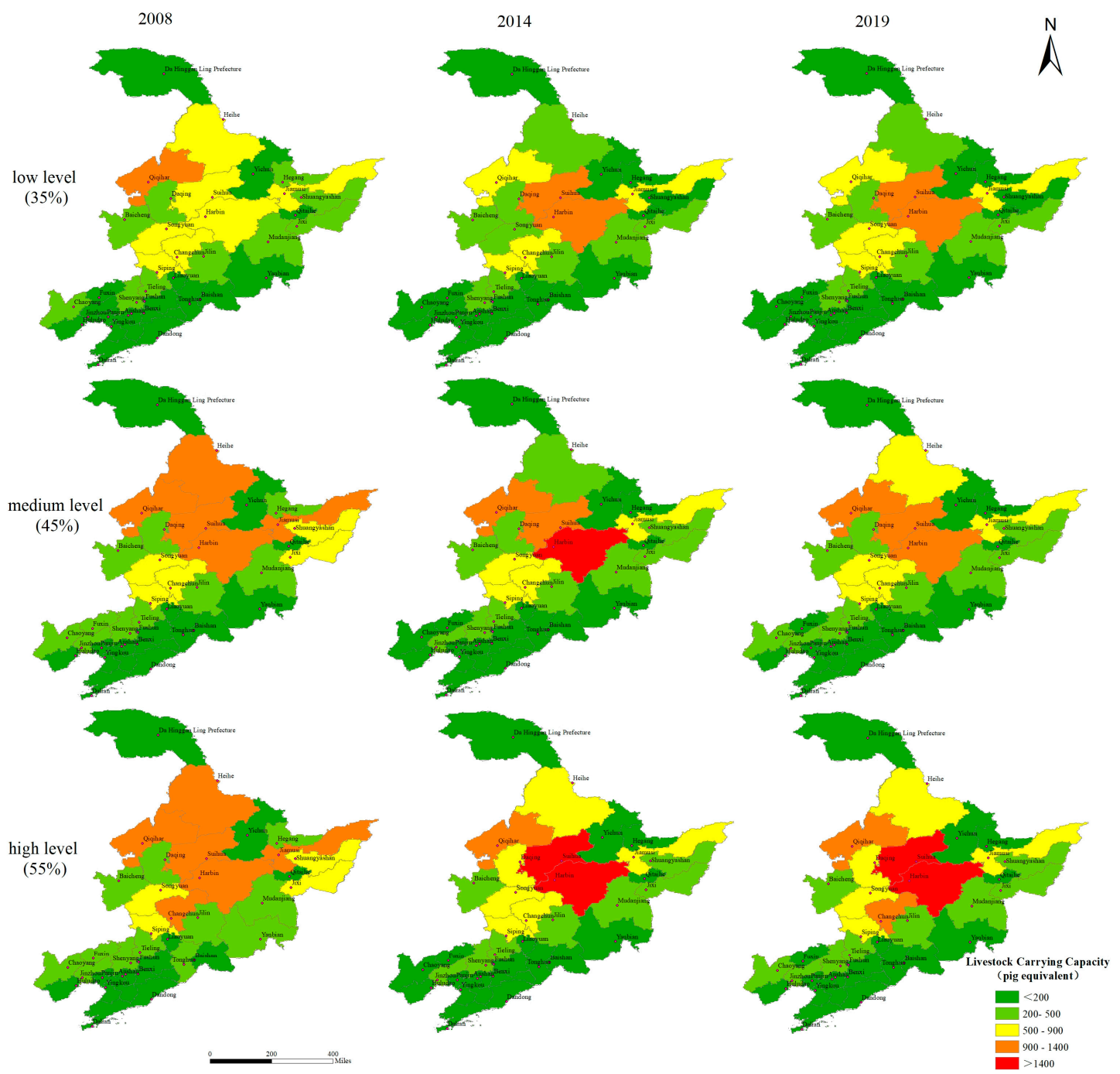

Figure 4. The livestock carrying capacity of farmland in the northeast region in 2008, 2014, and 2019.

\subsection{Changes in the Risk Coefficient of Regional Livestock Carrying Capacity of Farmland in the Northeast Region}

Figure 5 shows the risk coefficient of regional livestock carrying capacity of farmland under three scenarios where the proportion of nitrogen nutrient in fertilization is $35 \%, 45 \%$, and 55\%, respectively. On the whole, it can be clearly seen that the risk coefficient shows an upward trend; although the risk coefficient slightly decreased in 2019, most of the regions were still in the general risk area $(1<\mathrm{r}<2)$ and restricted area $(\mathrm{r} \geq 2)$. Under the scenario of $35 \%$, there were 13 regions in the potential area, which means the livestock production in these regions did not exceed the livestock carrying capacity of farmland in 2008, and most of these regions are located in Heilongjiang province. Additionally, there were 14 regions in the general risk area, which means that the livestock manure in these regions exceed the 
maximum value that can be absorbed by farmland, and cannot be fully utilized locally. If effective measures are not taken, this may cause pollution to the environment. Additionally, there are nine areas in the restricted area, which means that the livestock manure in these regions greatly exceeded the maximum value that the farmland can absorb, and most of these regions are located in Liaoning province. In 2019, the potential area decreased to 7, while the restricted area increased to 15, indicating that the regional ecological environment is facing a major threat. Additionally, it can still be concluded that if the proportion of nitrogen nutrient in fertilization is higher, the corresponding risk coefficient will be lower, which means that the farmland can absorb more livestock manure.

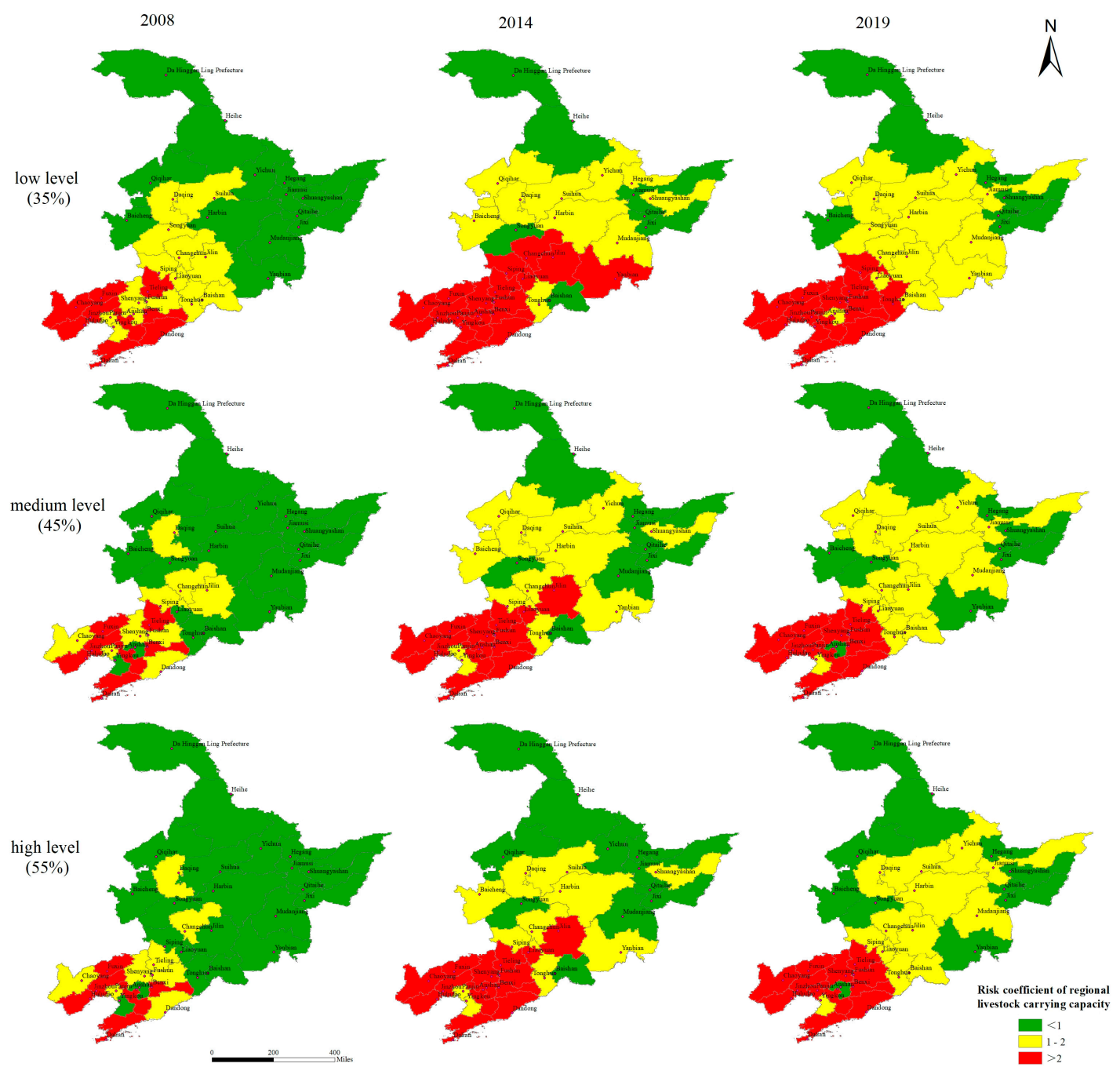

Figure 5. The risk coefficient of regional livestock carrying capacity of farmland in the northeast region in 2008, 2014, and 2019.

\section{Discussion}

In recent years, with the continuous transformation of northeast China's residents' dietary structure, the demand for animal products has been increasing, so the production scale of husbandry in this area has expanded significantly [40]. With the rise of modern large- and medium-sized husbandry enterprises, large-scale production has been realized in the breeding industry with intensive and factory-like characteristics. Large-scale breeding enterprises have achieved spatial concentration, but the degree of integration with agricultural production is becoming lower and lower. More and more manure is being produced, but the path for manure to return to farmland is becoming narrower and narrower. Zheng et al. (2019) also pointed that these changes can achieve large-scale economic 
growth in agricultural production and livestock manure treatment, but it often results in environmental pollution and waste of resources due to the uncoordinated structure of planting and breeding and the mismatch of planting and breeding spaces [41]. Behind this alienation, another important problem is that a large amount of manure that is difficult to digest in farmland is discharged into the ground and rivers in various ways, which seriously pollutes the environment and water resources, and this then evolves into an important environmental problem. Therefore, relocating the production activities of husbandry to the agricultural ecosystem, reconstructing the combination mode and ecological link between agriculture and husbandry, and ensuring the breeding waste is digested in the ecological circulation system of agriculture and husbandry are important ways to realize the sustainable utilization of farmland.

As for the changes in the livestock carrying capacity of farmland and risk coefficient, from the results we can see that although compared with 2008 the risk coefficient shows a significant improvement, some regions still have a decline compared with 2014, indicating that the relevant policies issued by governments to promote the adjustment of planting and breeding structure and the utilization of livestock manure resources have achieved certain results. However, it cannot be ignored that there were still 28 regions where the livestock manure exceed the maximum value that can be absorbed by farmland in 2019 . The regional ecological environment is facing huge challenges. Compared with the scenario where the proportion of nitrogen nutrient in fertilization is $35 \%$, the $55 \%$ scenario can absorb more livestock manure, and the corresponding risk level will be lower. However, from the perspective of agricultural production law, it is not the case that more fertilization is more beneficial to farmland protection and crop production. Excessive nitrogen elements may cause soil salinization, which is also not conducive to the sustainable use of farmland. $\mathrm{Fu}$ et al. (2020) also pointed that we cannot rely on excessive fertilization to improve farmland's absorption of livestock manure [32]. Additionally, from the regional distribution of the livestock carrying capacity, most of the restricted areas are concentrated in Liaoning Province, while most of the potential areas are concentrated in Heilongjiang Province. This also indicates that Liaoning Province urgently needs to take more scientific and effective measures in strengthening the adjustment of the planting and breeding structure and the utilization of livestock and poultry waste. Moreover, establishing a regulatory framework for grazing could also be an effective mitigation measure that also improves farmland quality. The degraded land can be restored by moderating grazing pressures rather than completely banning livestock grazing [42-44].

\section{Conclusions}

In this paper, we selected the northeast region as the study area from the perspective of soil nutrient demand; calculated the livestock carrying capacity of farmland under three scenarios where nitrogen nutrient accounts for 35\% (low level), 45\% (medium level), and 55\% (high level) of fertilization; and carried out a risk analysis. We found that the scale of husbandry breeding is expanding while the scale of the planting industry has remained basically unchanged. Compared with 2008, the livestock carrying capacity risk has displayed a significant improvement, but some regions still show a decline compared with 2014 . In the $35 \%$ scenario, the scale of livestock breeding in 29 out of 36 regions exceeded the actual carrying capacity level, and 15 of them belonged to restricted areas in 2019, which means that livestock waste in these regions far exceeds the capacity of farmland absorption, causing serious environmental problems in the long term. Additionally, the potential areas were mostly located in Heilongjiang Province, while the restricted areas were mostly located in Liaoning Province, which means that Liaoning province faces greater threats in the aspect of environmental pollution from livestock breeding. Moreover, in the case of mature organic fertilizer technology, the cross-regional deployment of organic fertilizers (from restricted area to potential area) is also an important way to resolve the environmental pollution of livestock and poultry manure. 
Therefore, the political implications of this paper include the following aspects: adjusting the structure of regional livestock breeding, improving the utilization rate of feed, and adopting measures such as manure reduction methods to reduce the output of manure nutrients; adjusting the regional planting industry structure and improving the output level of farmland crops to increase the ability to absorb manure; and promoting the development of the livestock manure processing industry and enhancing the production capacity of organic fertilizer. Additionally, in regions with suitable conditions, we should formulate policies to guide the regional allocation of the spatial layout of livestock farms and construct an integrated pattern of regional planting and breeding (Figure 6).

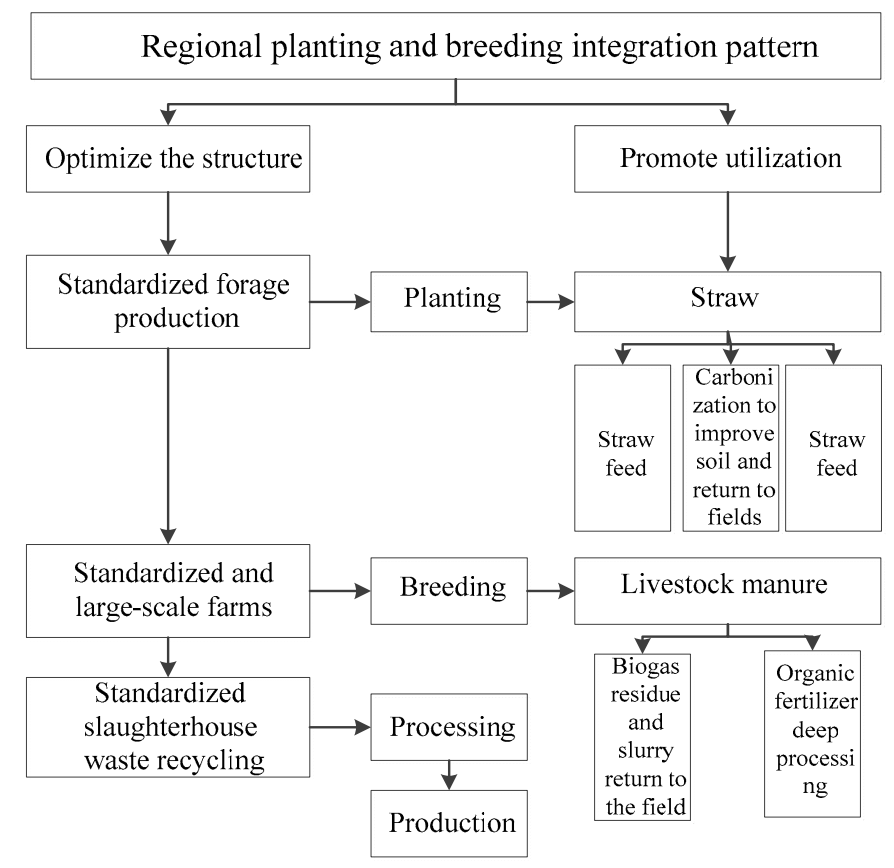

Figure 6. Schematic diagram of regional planting and breeding integration pattern.

Author Contributions: Conceptualization, X.D.; methodology, W.S. and Z.S.; writing-original draft preparation, Z.Z.; writing-review and editing, Z.L. and F.Z.; supervision, X.D.; project administration, X.Z. All authors have read and agreed to the published version of the manuscript.

Funding: This study was financially supported by the Strategic Priority Research Program of the Chinese Academy of Sciences (XDA23070400).

Data Availability Statement: The research data in this paper (amount of livestock and poultry breeding, sown area, annual crop yield, etc.) come from China Animal Husbandry Yearbook (2009-2020), Agricultural Statistical Yearbook (2009-2020), Heilongjiang Statistical Yearbook (2009-2020), Jilin Statistical Yearbook (2009-2020), Liaoning Statistical Yearbook (2009-2020), and related agricultural survey data; China's provincial administrative division data come from the National Science and Technology Basic Conditions Platform-Earth System Science Data Sharing Platform.

Conflicts of Interest: The authors declare no conflict of interest.

\section{References}

1. Xin, F.; Xiao, X.; Dong, J.; Zhang, G.; Zhang, Y.; Wu, X.; Li, X.; Zou, Z.; Ma, J.; Du, G.; et al. Large increases of paddy rice area, gross primary production, and grain production in Northeast China during 2000-2017. Sci. Total Environ. 2020, $711,135183$. [CrossRef] [PubMed]

2. Zhao, R.; Li, J.; Wu, K.; Kang, L. Cultivated land use zoning based on soil function evaluation from the perspective of black soil protection. Land 2021, 10, 605. [CrossRef]

3. Ge, Q.; Wang, J.; Zhu, H. Overall promotion of black soil protection and rural revitalization: Internal logic, main routes and policy Suggestions. Chin. Sci. Bull. 2021, 36, 1175-1183. 
4. Yu, X.; Ding, S.; Zou, Y.; Xue, Z.; Lyu, X.; Wang, G. Review of rapid transformation of floodplain wetlands in northeast China: Roles of human development and global environmental change. Chin. Geogr. Sci. 2018, 28, 654-664. [CrossRef]

5. Liu, T.; Wang, H.Z.; Xu, H. The spatiotemporal evolution of ecological security in China based on the ecological footprint model with localization of parameters. Ecol. Indic. 2021, 126, 107636. [CrossRef]

6. Han, X.; Zou, W.; Yang, F. Main Achievements, Challenges, and Recommendations of Black Soil Conservation and Utilization in China. Chin. Sci. Bull. 2021, 36, 1194-1202.

7. Cheng, H.; Zhu, L.; Meng, J. Fuzzy evaluation of the ecological security of land resources in mainland China based on the Pressure-State-Response framework. Sci. Total Environ. 2022, 804, 150053. [CrossRef]

8. Zhang, M.; Bao, Y.; Xu, J.; Han, A.; Liu, X.; Zhang, J.; Tong, Z. Ecological security evaluation and ecological regulation approach of East-Liao River basin based on ecological function area. Ecol. Indic. 2021, 132, 108255. [CrossRef]

9. Chen, N.; Qin, F.; Zhai, Y.; Cao, H.; Zhang, R.; Cao, F. Evaluation of coordinated development of forestry management efficiency and forest ecological security: A spatiotemporal empirical study based on China's provinces. J. Clean. Prod. 2020, $260,121042$. [CrossRef]

10. Wang, Y.; Li, Y. Promotion of degraded land consolidation to rural poverty alleviation in the agro-pastoral transition zone of northern China. Land Use Policy 2019, 88, 104114. [CrossRef]

11. Yang, Y.; Wang, K.; Liu, D.; Zhao, X.; Fan, J. Effects of land-use conversions on the ecosystem services in the agro-pastoral ecotone of northern China. J. Clean. Prod. 2020, 249, 119360. [CrossRef]

12. Pei, H.; Liu, M.; Shen, Y.; Xu, K.; Zhang, H.; Li, Y.; Luo, J. Quantifying impacts of climate dynamics and land-use changes on water yield service in the agro-pastoral ecotone of northern China. Sci. Total Environ. 2022, 809, 151153. [CrossRef] [PubMed]

13. Fang, J.; Yang, Y.; Ma, W.; Mohammat, A.; Shen, H. Ecosystem carbon stocks and their changes in China's grasslands. Sci. China Life Sci. 2010, 53, 757-765. [CrossRef] [PubMed]

14. Stefanidis, S.; Alexandridis, V.; Chatzichristaki, C.; Stefanidis, P. Assessing soil loss by water erosion in a typical mediterranean ecosystem of northern Greece under current and future rainfall erosivity. Water 2021, 13, 2002. [CrossRef]

15. Li, Y.; Li, J.; Are, K.S.; Huang, Z.; Yu, H.; Zhang, Q. Livestock grazing significantly accelerates soil erosion more than climate change in Qinghai-Tibet Plateau: Evidenced from 137Cs and 210Pbex measurements. Agric. Ecosyst. Environ. 2019, $285,106643$. [CrossRef]

16. Deng, X.; Gibson, J. Sustainable land use management for improving land eco-efficiency: A case study of hebei, China. Ann. Oper. Res. 2018, 290, 265-277. [CrossRef]

17. Guo, X.; Chang, Q.; Liu, X.; Bao, H.; Zhang, Y.; Tu, X.; Zhu, C.; Lv, C.; Zhang, Y. Multi-dimensional eco-land classification and management for implementing the ecological redline policy in China. Land Use Policy 2018, 74, 15-31. [CrossRef]

18. Zubair, M.; Wang, S.; Zhang, P.; Ye, J.; Liang, J.; Nabi, M.; Zhou, Z.; Tao, X.; Chen, N.; Sun, K.; et al. Biological nutrient removal and recovery from solid and liquid livestock manure: Recent advance and perspective. Bioresour. Technol. 2020, $301,122823$. [CrossRef]

19. Khoshnevisan, B.; Duan, N.; Tsapekos, P.; Awasthi, M.K.; Liu, Z.; Mohammadi, A.; Angelidaki, I.; Tsang, D.C.W.; Zhang, Z.; Pan, J.; et al. A critical review on livestock manure biorefinery technologies: Sustainability, challenges, and future perspectives. Renew. Sust. Energ. Rev. 2021, 135, 110033. [CrossRef]

20. Wu, Z.; Li, B.; Dai, X.; Hou, Y. Coupled Relationship between Rural Livelihoods and the Environment at a Village Scale: A Case Study in the Mongolian Plateau. Land 2020, 9, 38. [CrossRef]

21. Duan, Y.; Wang, H.; Huang, A.; Xu, Y.; Lu, L.; Ji, Z. Identification and spatial-temporal evolution of rural "production-livingecological" space from the perspective of villagers' behavior-A case study of Ertai Town, Zhangjiakou City. Land Use Policy 2021, 106, 105457. [CrossRef]

22. Deng, X.; Gibson, J. Improving eco-efficiency for the sustainable agricultural production: A case study in Shandong, China. Technol. Forecast. Soc. Chang. 2019, 144, 394-400. [CrossRef]

23. Li, J.; Liu, L. Determining the carrying capacity and environmental risks of livestock and poultry breeding in coastal areas of eastern China: An empirical model. Environ. Sci. Pollut. Res. 2020, 27, 7984-7995. [CrossRef]

24. Li, Y.; Yan, B.; Yan, J.; Shi, W. Estimation of Carrying Capacity of Livestock and Poultry Based on RS and GIS: A Case in Minhou County, Fuzhou City. Pol. J. Environ. Stud. 2021, 30, 227-234. [CrossRef]

25. Xu, Q.; Wang, X.; Xiao, B.; Hu, K. Rice-crab coculture to sustain cleaner food production in Liaohe River Basin, China: An economic and environmental assessment. J. Clean. Prod. 2019, 208, 188-198. [CrossRef]

26. Zhang, C.; Liu, S.; Wu, S.; Jin, S.; Reis, S.; Liu, H.; Gu, B. Rebuilding the linkage between livestock and cropland to mitigate agricultural pollution in China. Resour. Conserv. Recycl. 2019, 144, 65-73. [CrossRef]

27. Hristov, A.; Bannink, A.; Crompton, L.; Huhtanen, P.; Kreuzer, M.; McGee, M.; Nozière, P.; Reynolds, C.; Bayat, A.-R.; Yáñez-Ruiz, D.; et al. Invited review: Nitrogen in ruminant nutrition: A review of measurement techniques. J. Dairy Sci. 2019, 102, 5811-5852. [CrossRef]

28. Jin, S.; Zhang, B.; Wu, B.; Han, D.; Hu, Y.; Ren, C.; Zhang, C.; Wei, X.; Wu, Y.; Mol, A.P.J.; et al. Decoupling livestock and crop production at the household level in China. Nat. Sustain. 2021, 4, 48-55. [CrossRef]

29. McLellan, E.L.; Cassman, K.G.; Eagle, A.J.; Woodbury, P.B.; Sela, S.; Tonitto, C.; Marjerison, R.D.; Van Es, H.M. The nitrogen balancing act: Tracking the environmental performance of food production. Bioscience 2018, 68, 194-203. [CrossRef] 
30. Ali, A.I.; Wassie, S.E.; Korir, D.; Merbold, L.; Goopy, J.P.; Butterbach-Bahl, K.; Dickhoefer, U.; Schlecht, E. Supplementing tropical cattle for improved nutrient utilization and reduced enteric methane emissions. Animals 2019, 9, 210. [CrossRef]

31. Bai, Z.; Ma, W.; Ma, L.; Velthof, G.L.; Wei, Z.; Havlík, P.; Oenema, O.; Lee, M.R.F.; Zhang, F. China's livestock transition: Driving forces, impacts, and consequences. Sci. Adv. 2018, 4, eaar8534. [CrossRef] [PubMed]

32. Fu, Q.; Yin, G.; Yang, H.; Wang, W.; An, C. The Senario Analysis of China's Regional Livestock Carrying Capacity Risk of Farmland under the Principle of Planting-Breeding Balancing. Econ Geogr. 2020, 40, 164-172.

33. Norris, A.B.; Crossland, W.L.; Tedeschi, L.O.; Foster, J.L.; Muir, J.P.; Pinchak, W.E.; Fonseca, M.A. Inclusion of quebracho tannin extract in a high-roughage cattle diet alters digestibility, nitrogen balance, and energy partitioning. J. Anim. Sci. 2020, 98 , skaa047. [CrossRef]

34. Li, Y.; Sun, Z.; Accatino, F.; Hang, S.; Lv, Y.; Ouyang, Z. Comparing specialised crop and integrated crop-livestock systems in China with a multi-criteria approach using the emergy method. J. Clean. Prod. 2021, 314, 127974. [CrossRef]

35. You, H.; Yang, J.; Xue, B.; Xiao, X.; Xia, J.; Jin, C.; Li, X. Spatial evolution of population change in Northeast China during 1992-2018. Sci. Total Environ. 2021, 776, 146023. [CrossRef]

36. Zhao, H.; Zhai, X.; Guo, L.; Liu, K.; Huang, D.; Yang, Y.; Li, J.; Xie, S.; Zhang, C.; Tang, S.; et al. Assessing the efficiency and sustainability of wheat production systems in different climate zones in China using emergy analysis. J. Clean. Prod. 2019, 235, 724-732. [CrossRef]

37. Song, G.; Zhang, H. Cultivated land use layout adjustment based on crop planting suitability: A case study of typical counties in Northeast China. Land 2021, 10, 107. [CrossRef]

38. Yang, F.; Yang, S.; Zhu, Y.; Wang, J. Analysis of livestock and poultry breeding volume and nitrogen pollution load of cultivated land in China in recent 30 years. Trans. Chin. Soc. Agric. Eng. 2013, 29, 1-11.

39. Han, Z.; Han, C.; Yang, C. Spatial econometric analysis of environmental total factor productivity of ranimal husbandry and its influencing factors in China during 2001-2017. Sci. Total Environ. 2020, 723, 137726. [CrossRef]

40. Zhao, Z.; Wang, P.; Chen, J.; Zhang, F. Economic spillover effect of grass-based livestock husbandry on agricultural production-A case study in Hulun Buir, China. Technol. Forecast. Soc. Chang. 2021, 168, 120752. [CrossRef]

41. Zheng, L.; Zhang, Q.; Zhang, A.; Hussain, H.A.; Liu, X.; Yang, Z. Spatiotemporal characteristics of the bearing capacity of cropland based on manure nitrogen and phosphorus load in mainland China. J. Clean. Prod. 2019, 233, 601-610. [CrossRef]

42. Papanastasis, V.P.; Bautista, S.; Chouvardas, D.; Mantzanas, K.; Papadimitriou, M.; Mayor, A.G.; Koukioumi, P.; Papaioannou, A.; Vallejo, R.V. Comparative assessment of goods and services provided by grazing regulation and reforestation in degraded Mediterranean rangelands. Land Degrad. Dev. 2017, 28, 1178-1187. [CrossRef]

43. Kaltsas, D.; Panayiotou, E.; Kougioumoutzis, K.; Chatzaki, M. Overgrazed shrublands support high taxonomic, functional and temporal diversity of Mediterranean ground spider assemblages. Ecol. Indic. 2019, 103, 599-609. [CrossRef]

44. Panagopoulos, Y.; Dimitriou, E.; Skoulikidis, N. Vulnerability of a northeast Mediterranean island to soil loss. Can grazing management mitigate erosion? Water 2019, 11, 1491. [CrossRef] 